\title{
Hedyotis diffusa Willd extract inhibits HT-29 cell proliferation via cell cycle arrest
}

\author{
MINGHE LIN ${ }^{1,2}$, JIUMAO LIN ${ }^{2,4}$, LIHUI WEI $^{2}$, WEI XU ${ }^{3}$, ZHENFENG HONG $^{2}$, \\ QIAOYAN CAI ${ }^{2,4}$, JUN PENG ${ }^{2,4}$ and DEZENG ZHU ${ }^{1}$
}

\begin{abstract}
${ }^{1}$ Department of Traditional Chinese Medicine, Changhai Hospital, Second Military Medical University, Shanghai 200433; ${ }^{2}$ Academy of Integrative Medicine Biomedical Research Center; ${ }^{3}$ Department of Pharmacology; ${ }^{4}$ Fujian Key Laboratory of Integrative Medicine on Geriatrics, Fujian University of Traditional Chinese Medicine, Minhou Shangjie, Fuzhou, Fujian 350108, P.R. China
\end{abstract}

Received February 3, 2012; Accepted May 25, 2012

DOI: $10.3892 /$ etm.2012.599

\begin{abstract}
Hedyotis diffusa Willd (HDW) has long been used as an important component in several Chinese medicine formulae to clinically treat various types of cancer, including colorectal cancer (CRC). Previously, we reported that HDW inhibits CRC growth via the induction of cancer cell apoptosis and the inhibition of tumor angiogenesis. In the present study, to further elucidate the mechanism of HDW-mediated antitumor activity, we investigated the effect of HDW ethanol extract (EEHDW) on the proliferation of HT-29 human colon carcinoma cells. We found that EEHDW reduced HT-29 cell viability and survival in a dose- and time-dependent manner. We also observed that EEHDW treatment blocked the cell cycle, preventing $\mathrm{G} 1$ to $\mathrm{S}$ progression, and reduced mRNA expression of pro-proliferative PCNA, Cyclin D1 and CDK4, but increased that of anti-proliferative p21. Our findings suggest that Hedyotis diffusa Willd may be an effective treatment for CRC via the suppression of cancer cell proliferation.
\end{abstract}

Correspondence to: Dr Jun Peng, Academy of Integrative Medicine, Fujian University of Traditional Chinese Medicine, 1 Huatuo Road, Minhou Shangjie, Fuzhou, Fujian 350108, P.R. China

E-mail: pjunlab@hotmail.com

Dr Dezeng Zhu, Department of Traditional Chinese Medicine, Changhai Hospital, Second Military Medical University, 168 Changhai Road, Shanghai 200433, P.R. China

E-mail: zdzzyx@163.com

Abbreviations: EEHDW, ethanol extract of Hedyotis diffusa Willd; CRC, colorectal cancer; DMSO, dimethyl sulfoxide; MTT, 3-(4,5-dimethyl-thiazol-2-yl)-2,5-diphenyltetrazolium bromide

Key words: proliferation, cell cycle, Chinese herbal medicine, colorectal cancer, Hedyotis diffusa Willd

\section{Introduction}

Cancer cells are characterized by uncontrolled proliferation (1), therefore inhibiting the excessive proliferation of tumor cells is one of the key approaches for the development of anti-cancer drugs. Eukaryotic cell proliferation is regulated by the cell cycle, which is divided into a series of phases. G1/S transition is one of the two main checkpoints that control cell cycle progression (2). G1/S progression is mainly regulated by Cyclin D1 and Cyclin-dependent kinase 4 (CDK4) $(3,4)$. PCNA is an acidic nuclear protein that has been recognized as a histological marker for the G1/S phase in the cell cycle (5). p21 is a CDK inhibitor, which can bind to CDK-Cyclin complexes and alter their function in order to suppress cell proliferation (6).

Drug resistance and toxicity against normal cells limit the effectiveness of current chemotherapies for the treatment of colorectal cancer (CRC) (7-10), which is a serious public health problem worldwide (11). These problems highlight the urgent need for the development of novel cancer chemotherapies. Recently, natural products have received great interest since they have relatively few side effects compared with modern chemotherapeutics and have been used clinically for thousands of years as significant alternative remedies for a variety of diseases including cancer (12-17). One promising medicinal plant is Hedyotis diffusa Willd (HDW) that belongs to the Rubiaceae family and is widely distributed throughout Northeast Asia. As a well-known traditional Chinese folk-medicine, it is used for heat-clearing, detoxification, promotion of blood circulation and the removal of blood stasis (18). HDW has also long been used as an significant component in several Chinese medicine formulae to treat various types of cancer, including CRC (18-20). Previously, we reported that Hedyotis diffusa Willd inhibits the growth of $\mathrm{CRC}$, likely via the induction of cancer cell apoptosis and the inhibition of tumor angiogenesis $(21,22)$. To further elucidate the mechanism of the tumoricidal activity of HDW we investigated its effect on the proliferation of human colon carcinoma HT-29 cells. 


\section{Materials and methods}

Materials and reagents. Dulbecco's modified Eagle's medium (DMEM), fetal bovine serum (FBS), penicillin-streptomycin, Trypsin-EDTA and TRIzol reagent were purchased from Invitrogen (Carlsbad, CA, USA). SuperScript II reverse transcriptase was obtained from Promega (Madison, WI, USA). All other chemicals, unless otherwise stated, were obtained from Sigma Chemicals (St. Louis, MO, USA).

Preparation of ethanol extract of Hedyotis diffusa Willd $(E E H D W)$. EEHDW was prepared as described previously $(20,21)$. Briefly, stock solutions of EEHDW were prepared by dissolving the EEHDW powder in $40 \%$ DMSO to a final concentration of $400 \mathrm{mg} / \mathrm{ml}$ and stored at $-20^{\circ} \mathrm{C}$. The working concentrations of EEHDW were made by diluting the stock solution in the culture medium. The final concentrations of DMSO in the medium were $<0.5 \%$.

Cell culture. Human colon carcinoma HT-29 cells were obtained from the American Type Culture Collection (ATCC, Manassas, VA, USA). HT-29 cells were grown in DMEM. DMEM was supplemented with $10 \%$ (v/v) FBS, 100 units/ml penicillin and $100 \mu \mathrm{g} / \mathrm{ml}$ streptomycin. Cells were cultured at $37^{\circ} \mathrm{C}$ and $5 \% \mathrm{CO}_{2}$ in a humidified environment.

Cell viability evaluation. Cell viability was assessed by MTT colorimetric assay. HT-29 cells were seeded into 96 -well plates at a density of $1 \times 10^{4}$ cells/well in $0.1 \mathrm{ml}$ medium. The cells were treated with various concentrations $(0,1,3$ and $5 \mathrm{mg} / \mathrm{ml})$ of EEHDW for various periods of time. At the end of the treatment, $10 \mu \mathrm{l}$ MTT $(5 \mathrm{mg} / \mathrm{ml}$ in phosphate-buffered saline, PBS) was added to each well and the samples were incubated for an additional $4 \mathrm{~h}$ at $37^{\circ} \mathrm{C}$. The purple-blue MTT formazan precipitate was dissolved in $100 \mu \mathrm{l}$ DMSO. The absorbance was measured at $570 \mathrm{~nm}$ using an ELISA reader (BioTek, Model ELX800, Winooski, VT, USA).

Colony formation assay. The HT-29 cells were seeded into 6 -well plates at a density of $2 \times 10^{5}$ cells/well and treated with various concentrations $(0,1,3$ and $5 \mathrm{mg} / \mathrm{ml})$ of EEHDW for $24 \mathrm{~h}$. The cells were then diluted in fresh medium in the absence of EEHDW and reseeded into 6-well plates at a density of $1.5 \times 10^{3}$ cells/well. Following incubation for 7 or 8 days in a $37^{\circ} \mathrm{C}$ humidified incubator with $5 \% \mathrm{CO}_{2}$, the colonies were counted under a light microscope. Cell survival was calculated by normalizing the survival of the control cells as $100 \%$.

Cell cycle analysis. The cell cycle analysis was carried out by flow cytometry using a fluorescence-activated cell sorting (FACS) MoFlo XDP (Beckman Coulter, Miami, FL, USA) and propidium iodide (PI) staining. Following treatment with the indicated concentrations $(0,1,3$ and $5 \mathrm{mg} / \mathrm{ml})$ of EEHDW for $24 \mathrm{~h}, \mathrm{HT}-29$ cells were harvested and adjusted to a concentration of $1 \times 10^{6}$ cells $/ \mathrm{ml}$, then fixed in $70 \%$ ethanol at $4^{\circ} \mathrm{C}$ overnight. The fixed cells were washed twice with cold PBS and then incubated for $30 \mathrm{~min}$ with RNase $(8 \mu \mathrm{g} / \mathrm{ml})$ and PI $(10 \mu \mathrm{g} / \mathrm{ml})$. The fluorescent signal was detected through the FL2 channel and the proportion of DNA in various phases was

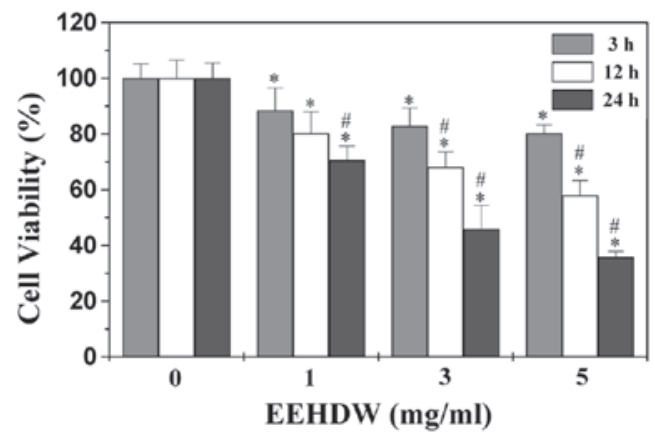

Figure 1. Effect of EEHDW on HT-29 cell viability. Cells were treated with various concentrations of EEHDW for the indicated time periods. Cell viability was determined by MTT assay. The data were normalized to the viability of control cells (100\%, treated with $0.5 \%$ DMSO vehicle). Data are means with SD (standard deviation; error bars) from at least three independent experiments. ${ }^{*} \mathrm{P}<0.05$, versus untreated control cells; ${ }^{~} \mathrm{P}<0.05$, versus cells treated for $3 \mathrm{~h}$ with the same dose of EEHDW. EEHDW, ethanol extract of Hedyotis Diffusa Willd.

analyzed using ModfitLT Version 3.0 (Verity Software House, Topsham, ME, USA).

RNA extraction and RT-PCR analysis. A total of $2 \times 10^{5}$ HT- 29 cells were seeded into 6-well plates in $2 \mathrm{ml}$ medium and treated with indicated concentrations $(0,1,3$ and $5 \mathrm{mg} / \mathrm{ml})$ of EEHDW for $24 \mathrm{~h}$. Total RNA was isolated using TRIzol reagent. Oligo(dT)-primed RNA (1 $\mu \mathrm{g})$ was reverse-transcribed with SuperScript II reverse transcriptase (Promega) according to the manufacturer's instructions. The obtained cDNA was used to determine the mRNA levels of Cyclin D1, CDK4, PCNA and p21 by PCR. GAPDH was used as an internal control. The sequences of the primers used for amplification of Cyclin D1, CDK4, PCNA, p21 and GAPDH transcripts are as follows: Cyclin D1 forward 5'-TGGATGCTGGAGGTCTGCGAG GAA-3' and reverse 5'-GGCTTCGATCTGCTCCTGGCA GGC-3' [Temperature (Tm), $55^{\circ} \mathrm{C} ; 573 \mathrm{bp}$ ]; CDK4 forward 5'-CATGTAGACCAGGACCTAAGC-3' and reverse 5'-AAC TGGCGCATCAGATCCTAG-3' (Tm, 58 ${ }^{\circ} \mathrm{C}$; 206 bp); PCNA forward 5'-GCTGACATGGGACACTTA-3', and reverse 5'-CTCAGGTACAAACTTGGTG-3' (Tm, 56 ${ }^{\circ} \mathrm{C}$; $610 \mathrm{bp}$ ); p21 forward 5'-GCGACTGTGATGCGCTAATGG-3', and reverse $5^{\prime}$-TAGAAATCTGTCATGCTGGTCTGC- $3^{\prime} \quad\left(\mathrm{Tm}=55^{\circ} \mathrm{C}\right.$, $358 \mathrm{bp}$ ); GAPDH forward 5'-CGACCACTTTGTCAAG CTCA3', and reverse 5'-AGGGGTCTACATGGCAACTG-3' (Tm, $58^{\circ} \mathrm{C} ; 240 \mathrm{bp}$ ). Samples were analyzed by gel electrophoresis (1.5\% agarose). The DNA bands were examined using a Gel Documentation system (BioRad, Model Gel Doc 2000, USA).

Statistical analysis. All data were expressed as the means of three independent experiments and data was analyzed using the SPSS package for Windows (Version 11.5; Chicago, IL, USA). Statistical analysis of the data was performed using a Student's t-test and ANOVA. $\mathrm{P}<0.05$ was considered to indicate a statistically significant result.

\section{Results}

EEHDW inhibits the proliferation of HT-29 cells. We examined the effect of EEHDW on HT-29 cell viability by MTT 


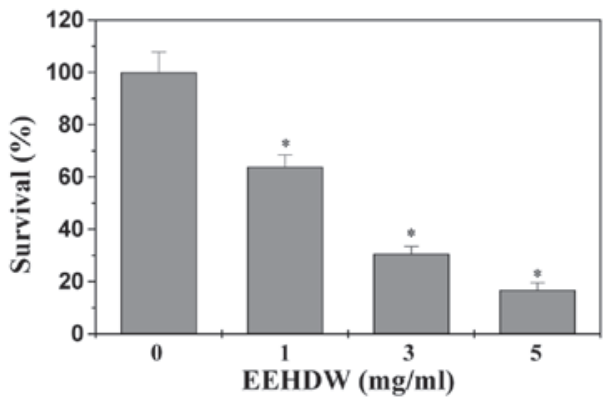

Figure 2. Effect of EEHDW on HT-29 cell survival. Cells were treated with indicated concentrations of EEHDW for $24 \mathrm{~h}$. Cell survival was determined by colony formation analysis. The data were normalized to the survival of control cells. Data are averages with SD (standard deviation; error bars) from at least three independent experiments. ${ }^{*} \mathrm{P}<0.05$, versus control cells. EEHDW, ethanol extract of Hedyotis diffusa Willd.

A

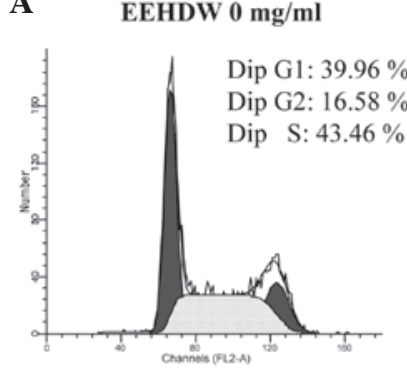

EEHDW $3 \mathrm{mg} / \mathrm{ml}$

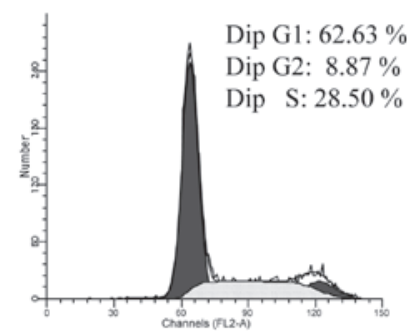

B

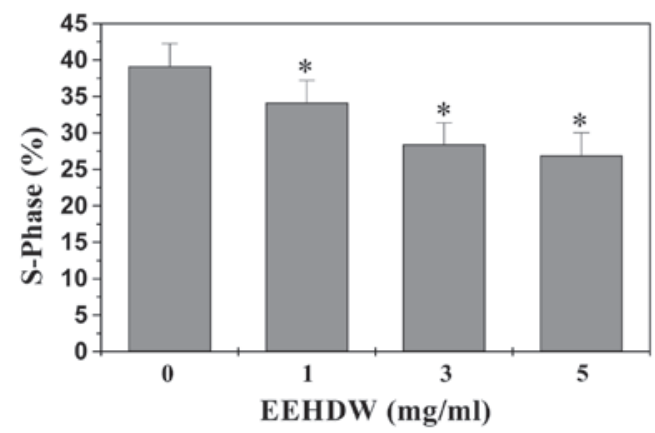

Figure 3. Effect of EEHDW on the cell cycle progression of HT-29 cells. (A) Cells were treated with indicated concentrations of EEHDW for $24 \mathrm{~h}$, stained with PI and analyzed by FACS. Images are representative of three independent experiments. (B) The proportion of DNA in S phase was calculated using ModfitLT Version 3.0 Software. Data shown are averages with $\mathrm{SD}$ (standard deviation; error bars) from three independent experiments. ${ }^{*} \mathrm{P}<0.05$, versus control cells. FACS, fluorescence-activated cell sorting; EEHDW, ethanol extract of Hedyotis diffusa Willd; PI, propidium iodide.

assay. As shown in Fig. 1, EEHDW treatment reduced cell viability in a dose- and time-dependent manner compared

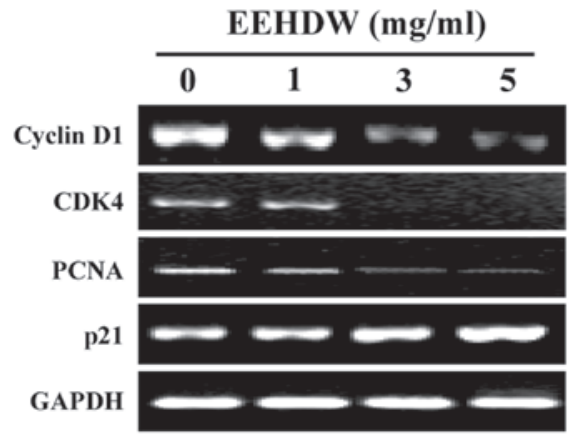

Figure 4. Effect of EEHDW on the mRNA expression of Cyclin D1, CDK4, PCNA and p21 in HT-29 cells. Cells were treated with the indicated concentrations of EEHDW for $24 \mathrm{~h}$. The mRNA levels of Cyclin D1, CDK4, PCNA and p21 were determined by RT-PCR. GAPDH was used as an internal control. Data are representative of three independent experiments. EEHDW, ethanol extract of Hedyotis diffusa Willd; CDK4, Cyclin-dependent kinase 4.

to untreated control cells $(\mathrm{P}<0.05)$. The cell viability was decreased to $36 \%$ at the highest concentration of EEHDW $(5 \mathrm{mg} / \mathrm{ml})$ at $24 \mathrm{~h}$ in this study. To further verify these results, we examined the effect of EEHDW on HT-29 cell survival using a colony formation assay. As shown in Fig. 2, treatment with 1,3 and $5 \mathrm{mg} / \mathrm{ml}$ of EEHDW for $24 \mathrm{~h}$ reduced the cell survival rate in a dose-dependent manner by 34,70 and $84 \%$ compared to untreated control cells $(\mathrm{P}<0.05)$. These data suggest that EEHDW inhibits HT-29 cell proliferation.

EEHDW blocks G1/S progression of HT-29 cells. The G1/S transition is one of the two main checkpoints that regulate cell cycle progression and thus the cell proliferation. We, therefore, investigated the effect of EEHDW on the G1 to S progression in HT-29 cells via PI staining followed by FACS analysis. As shown in Fig. 3A and B, the percentage of S-phase cells following treatment with $0,1,3$ and $5 \mathrm{mg} / \mathrm{ml}$ of EEHDW was $39.13,34.14,28.42$ and $26.91 \%$, respectively $(\mathrm{P}<0.05)$, indicating that EEHDW inhibits HT-29 cell proliferation by blocking the cell cycle at the G1 to S progression.

EEHDW regulates $m R N A$ expression of PCNA, Cyclin D1, $C D K 4$ and $p 21$. We examined the effect of EEHDW on the mRNA expression of the pro-proliferative PCNA, Cyclin D1, CDK4, and the anti-proliferative p21 using RT-PCR. As shown in Fig. 4, EEHDW treatment markedly reduced the mRNA expression of PCNA, Cyclin D1 and CDK4, but increased that of $\mathrm{p} 21$.

\section{Discussion}

Hedyotis diffusa Willd (HDW) is a Chinese medicinal herb with numerous reported pharmacological applications. HDW is clinically effective in the treatment of various types of cancer, including CRC (18-20). Recently, we reported that the direct cytotoxic effect of HDW on colon cancer cells is partially due to the induction of mitochondrion-dependent apoptosis (21). However, the effect of HDW on cancer cell proliferation is still unclear.

Using MTT and colony formation assays, in the present study, we demonstrated that the ethanol extract of Hedyotis 
diffusa Willd (EEHDW) inhibited the proliferation of human colon carcinoma HT-29 cells. Cell proliferation is regulated by the cell cycle, which consists of four periods; $\mathrm{S}$ phase (DNA synthesis), M phase (mitosis), G1 and G2 phase. The $\mathrm{G} 1 / \mathrm{S}$ transition is one of the two main checkpoints of the cell cycle (2), and is responsible for the initiation and completion of DNA replication. By using FACS analysis and PI staining we observed that the inhibitory effect of EEHDW on HT-29 cell proliferation was associated with the prevention of G1 to $\mathrm{S}$ transition. The $\mathrm{G} 1 / \mathrm{S}$ progression is strongly regulated by Cyclin D1 which forms an active complex with its CDK major catalytic partners (CDK4/6) $(3,4)$. An unchecked or hyperactivated Cyclin D1/CDK4 complex may be responsible for enhanced cellular proliferation. PCNA, a 36-kDa DNA polymerase delta auxiliary protein that is involved in cell proliferation and is specifically expressed in proliferating cell nuclei, has been recognized as a histological marker for the G1/S phase in the cell cycle (5). As a proliferation inhibitor, $\mathrm{p} 21$ protein plays a role in G1 arrest by binding to and inhibiting the activity of Cyclin-CDK complexes and PCNA (6). Therefore, the expression of PCNA, CDK4, Cyclin D1 and p21 reflects the proliferation state of HT-29 cells to some extent. As predicted, following EEHDW treatment the mRNA expression of Cyclin D1, CDK4 and PCNA in HT-29 cells was downregulated but that of p21 was upregulated.

In conclusion, we report for the first time that EEHDW inhibits the proliferation of HT-29 cells via cell cycle arrest. Together with our previous study, these results suggest that Hedyotis diffusa Willd inhibits cancer progression via multiple mechanisms, including the induction of cancer cell apoptosis, inhibition of cell proliferation and tumor angiogenesis.

\section{Acknowledgements}

This work was sponsored by the Natural Science Foundation of Fujian Province of China (2010J01195), the Research Foundation of the Education Bureau of Fujian Province of China (JA10162) and the Developmental Fund of Chen Keji Integrative Medicine (CKJ 2010030).

\section{References}

1. Evan GI and Vousden KH: Proliferation, cell cycle and apoptosis in cancer. Nature 411: 342-348, 2001.

2. Nurse P: Ordering $S$ phase and $M$ phase in the cell cycle. Cell 79: 547-550, 1994
3. Chen Y, Robles AI, Martinez LA, Liu F, Gimenez-Conti IB and Conti CJ: Expression of G1 cyclins, cyclin-dependent kinases, and cyclin-dependent kinase inhibitors in androgen-induced prostate proliferation in castrated rats. Cell Growth Differ 7: 1571-1578, 1996.

4. Graña X and Reddy EP: Cell cycle control in mammalian cells: role of cyclins, cyclin dependent kinases (CDKs), growth suppressor genes and cyclin-dependent kinase inhibitors (CKIs). Oncogene 11: 211-219, 1995.

5. Zhong W, Peng J, He H, Wu D, Han Z, Bi X and Dai Q: Ki-67 and PCNA expression in prostate cancer and benign prostatic hyperplasia. Clin Invest Med 31: E8-E15, 2008.

6. Harper JW, Adami GR, Wei N, Keyomarsi K and Elledge SJ: The p21 Cdk-interacting protein Cip1 is a potent inhibitor of G1 cyclin-dependent kinases. Cell 75: 805-816, 1993.

7. Gustin DM and Brenner DE: Chemoprevention of colon cancer: current status and future prospects. Cancer Metast Rev 21: 323-348, 2002

8. Gorlick R and Bertino JR: Drug resistance in colon cancer. Semin Oncol 26: 606-611, 1999.

9. Longley DB, Allen WL and Johnston PG: Drug resistance, predictive markers and pharmacogenomics in colorectal cancer. Biochim Biophys Acta 1766: 184-196, 2006.

10. Boose G and Stopper H: Genotoxicity of several clinically used topoisomerase II inhibitors. Toxicol Lett 116: 7-16, 2000.

11. Jemal A, Bray F, Center MM, Ferlay J, Ward E and Forman D: Global cancer statistics. CA Cancer J Clin 61: 69-90, 2011.

12. Kelloff GJ: Perspectives on cancer chemoprevention research and drug development. Adv Cancer Res 78: 199-334, 2000.

13. Tyagi AK, Singh RP, Agarwal C, Chan DC and Agarwal C: Silibinin strongly synergizes human prostate carcinoma DU145 cells to doxorubicin-induced growth inhibition, G2-M arrest, and apoptosis. Clin Cancer Res 8: 3512-3519, 2002.

14. Newman DJ, Cragg GM and Snader KM: The influence of natural products upon drug discovery. Nat Prod Rep 17: 215-234, 2000.

15. Jeune MA, Kumi-Diaka J and Brown J: Anticancer activities of pomegranate extracts and genistein in human breast cancer cells. J Med Food 8: 469-475, 2005.

16. Sausville EA: Versipelostatin: unfolding an unsweetened death. J Natl Cancer Inst 96: 1266-1267, 2004.

17. Won HJ, Han CH, Kim YH, Kwon HJ, Kim BW, Choi JS and Kim KH: Induction of apoptosis in human acute leukemia Jurkat $\mathrm{T}$ cells by Albizzia julibrissin extract is mediated via mitochondria-dependent caspase-3 activation. J Ethnopharmacol 106: 383-389, 2006.

18. Song LR: Zhonghuabencao. Vol 61. Shanghai Science and Technology Press, Shanghai, pp433, 1999.

19. Yang JJ, Hsu HY, Ho YH and Lin CC: Comparative study on the immunocompetent activity of three different kinds of Peh-Hue-Juwa-Chi-Cao, Hedyotis diffusa, H. corymbosa and Mollugo pentaphylla after sublethal whole body X-irradiation. Phytother Res 11: 428-432, 1997.

20. Li R, Zhao HR and Lin YM: Anti-tumor effect and protective effect on chemotherapeutic damage of water soluble extracts from Hedyotis diffusa. J Chin Pharm Sci 11: 54-58, 2002.

21. Lin JM, Chen YQ, Wei LH, Chen XZ, Xu W, Hong ZF, Sferra TJ and Peng J: Hedyotis Diffusa Willd extract induces apoptosis via activation of the mitochondrion-dependent pathway in human colon carcinoma cells. Int J Oncol 37: 1331-1338, 2010.

22. Lin JM, Wei LH, Xu W, Hong ZF, Liu XX and Peng J: Effect of Hedyotis Diffusa Willd extract on tumor angiogenesis. Mol Med Rep 4: 1283-1288, 2011. 